\title{
Editorial: Relaunching Marketing Letters
}

\author{
Eric T. Bradlow ${ }^{1} \cdot$ Peter N. Golder $^{2}$ - Joel Huber ${ }^{3} \cdot$ Sandy Jap $^{4}$. \\ Aparna A. Labroo ${ }^{5}$. Donald R. Lehmann ${ }^{6}$. John Lynch ${ }^{7}$ - Natalie Mizik ${ }^{8}$. \\ Russell S. Winer ${ }^{9}$
}

Published online: 12 November 2020

C) Springer Science+Business Media, LLC, part of Springer Nature 2020

Marketing Letters is a unique and essential journal for the marketing discipline. Don Lehmann's founding vision has always been that its role is to quickly disseminate interesting and provocative ideas into our discipline for discussion and debate and to spur further research. His founding editorial described the contents of the journal as "interesting papers [that] will make readers say 'I learned something,' 'it made me think,' and 'I wish I had done this'." Interesting papers may run counter to intuition or existing empirical evidence, overthrow existing theories, establish new theories, highlight emerging opportunities for investigation, and contribute toward empirical generalizations.

The journal is now in its fourth decade of quickly disseminating interesting research ideas, and findings to the marketing community. In keeping with its founding, we have a number of exciting new initiatives to announce along with a new editorial team to bring these initiatives to fruition.

\section{New editorial team(s)}

On January 1, 2021, Aparna Labroo, Natalie Mizik, and Russ Winer will become the new editors-in-chief of Marketing Letters. They bring an abundance of research expertise across a wide spectrum of marketing topics and methodological approaches. The transition from two to three editors-in-chief reflects the success of the journal, which is now on track to receive over 450 new paper submissions in 2020. The editorsin-chief will handle traditional submissions constituting the main track of papers for the journal.

This editorial incorporates material from two prior editorials (Golder et al. 2017; Golder and Jap 2020). We particularly encourage those interested in submitting an Idea Corner paper to read these two editorials as well as current Idea Corner publications.

Sandy Jap

sjap@emory.edu

Extended author information available on the last page of the article 
The outgoing editors-in-chief, Peter Golder and Sandy Jap, will continue to handle all manuscripts on which they made the initial editorial decision. In 2021, they will become co-editors of the journal's Idea Corner track, which emphasizes short submissions on emerging trends. We are also delighted to announce a new initiative for the journal and its editorial team. In 2021, we will launch Marketing Letters' Replication Corner track. This track will continue the initiative originally launched at International Journal of Research in Marketing and subsequently hosted at Journal of Marketing Behavior. The original editorial team of Eric Bradlow, Joel Huber, Don Lehmann, and John Lynch will be co-editors of this track for the first year of its relaunch at Marketing Letters.

\section{New tracks and review processes}

\subsection{Main track}

This track will consist of Marketing Letters' traditional, thought-provoking papers and be the largest track of the journal. These papers should be novel and not reasonably anticipated based on established theory or previous empirical research. Initial submissions to the main track should be a maximum of 4000 words (inclusive of abstract, main text, and references). The editors may allow revisions to go up to 5000 words. These papers may also include up to four tables and/or figures, which will not be counted toward the word limit. Additional material can be included in a web appendix. Marketing Letters is committed to maintaining a review process without Area Editors. The reason for this structure is the belief that interesting ideas are more likely to be published with fewer intermediaries in the review process. Authors may request one of the three editors-in-chief to handle their manuscript or be randomly assigned among them. Regardless, the same evaluation criteria will be applied as they seek articles of broad interest to the entire marketing field. Before sending a paper out for review, each paper will be read and screened to see if it satisfies the journal's mission of publishing interesting, provocative papers. The journal's desk reject rate will be high if authors do not screen their papers on these criteria prior to submission. Such desk rejections will help us better manage and preserve the resources of our world-class editorial review board and provide fast feedback for papers that are consistent (and inconsistent) with the journal's positioning. Marketing Letters' reviews are typically shorter than other journals' reviews as the goal is to emphasize interesting ideas and certify the methods employed. This approach is also consistent with the journal's principle that papers belong to authors and not reviewers. Our goal is to (conditionally) accept or reject a paper by the second round of reviews.

\subsection{Idea Corner track}

Idea Corner papers should identify and document a novel marketplace phenomenon and then develop an initial conceptualization with an emphasis on the future research agenda for that phenomenon. Other types of Idea Corner papers could include (i) a set of papers on a multi-disciplinary topic addressed by researchers from a variety of disciplines, research perspectives, and methods; (ii) tributes to luminaries in marketing 
academics placing their contributions in the context of the broader marketing literature and identifying remaining opportunities for future research; (iii) novel ideas, concepts, and research directions emanating from a conference; and (iv) essays on research practices and ethical norms in marketing. Importantly, the emphasis of any Idea Corner paper should be on the research implications and directions that could fundamentally shape our thinking into the future. Please contact the track co-editors with a proposed idea that fits one of these four other types of Idea Corner papers before writing an entire paper. Idea Corner submissions should be a maximum of 2000 words (inclusive of abstract, main text, and a maximum of 20 references), and up to two tables and/or figures. Additional material can be included in a web appendix. Idea Corner submissions will be reviewed by the track co-editors. Papers will be reviewed once with a decision to either (conditionally) accept or reject. Accepted papers will appear in the first issue after acceptance.

\subsection{Replication Corner track}

The goal of this section is to replicate and extend the most interesting and impactful papers in our field in order to consolidate and expand our collective knowledge base (Lynch Jr. et al 2015). Replication Corner papers present complementary work on important existing published papers (in terms of citations in marketing and/or the topic itself) in order to help establish empirical generalizations and/or boundary conditions or moderators of an effect. We recognize that no single paper is perfect/conclusive and that the only way to establish generalizations is through multiple authors exploring an issue using both similar and dissimilar methods. For these reasons, the Replication Corner encourages conceptual replications and replications with extension. In a conceptual replication, authors attempt to test the same construct and relationships as the original paper but with different operationalizations of independent and dependent variables. In replication with extension, the authors provide both a relatively "close" replication of the original with similar operational independent and dependent variables, and an extension that varies at least one critical factor in the original study. While replication papers tend to be behavioral papers, we strongly encourage replications of empirical, quantitative work based on alternative settings, datasets, field experiments, etc. in order to generalize these types of results. Replication Corner submissions should be a maximum of 4000 words (inclusive of abstract, main text, and references), and up to three tables and/or figures (not counting toward word limit). Additional material can be included in a web appendix.

\section{Conclusion}

The rationale for Marketing Letters is as strong as ever. The advancement of our field rests upon generating interesting, provocative ideas and getting those ideas into the marketplace rapidly in order to be debated, tested, refined, and sometimes rejected. Marketing Letters' streamlined review process provides an alternative to the increasingly protracted review process at other journals, freeing up authors' and reviewers'

scarce time for generating and disseminating even more research insights. The journal's new initiatives and new editorial team are committed to Marketing Letters continuing to fulfill the unique vision upon which it was founded. 


\section{References}

Golder, P. N., \& Jap, S. D. (2020). Launching the Idea Corners section of Marketing Letters. Marketing Letters, 31, 1-2.

Golder, P. N., Jap, S., \& Steckel, J. H. (2017). The future of Marketing Letters: vision, review process, and a new type of paper-idea corners. Marketing Letters, 28, 335-339.

Lynch Jr., J. G., Bradlow, E. T., Huber, J. C., \& Lehmann, D. R. (2015). Reflections on the replication corner: in praise of conceptual replications. International Journal of Research in Marketing, 32(4), 333-342.

Publisher's note Springer Nature remains neutral with regard to jurisdictional claims in published maps and institutional affiliations.

\section{Affiliations}

\section{Eric T. Bradlow ${ }^{1}$ - Peter N. Golder ${ }^{2}$ - Joel Huber ${ }^{3}$ - Sandy Jap ${ }^{4}$ - Aparna A.} Labroo $^{5} \cdot$ Donald R. Lehmann $^{6} \cdot$ John Lynch $^{7} \cdot$ Natalie Mizik $^{8} \cdot$ Russell S. Winer $^{9}$

1 University of Pennsylvania, 761 Jon M. Huntsman Hall, 3730 Walnut Street, Philadelphia, PA 19104, USA

2 Tuck School of Business, Dartmouth College, 100 Tuck Hall, Hanover, NH 03755, USA

3 Duke University: The Fuqua School of Business, 100 Fuqua Drive, Durham, NC 27708, USA

4 Emory University Goizueta Business School, 1300 Clifton Road, Atlanta, GA 30322, USA

5 Kellogg School of Management, Northwestern University, 2211 Campus Drive, Evanston, IL 60208, USA

6 Columbia Business School, 3022 Broadway, New York, NY 10027, USA

7 Leeds School of Business, University of Colorado-Boulder, 995 Regent Drive, Koelbel Building, 419 UCB, Boulder, CO 80309-0419, USA

8 Foster School of Business, University of Washington, Seattle, WA 98195, USA

9 Leonard N. Stern School of Business, New York University, Tisch Hall, 40 West Fourth Street, Rm. 910, New York, NY 10012, USA 